\title{
Customer Journey Construction of the Indonesian Open- Education Resources Platform
}

https://doi.org/10.3991/ijet.v14i24.12045

Harry B. Santoso $\left.{ }^{(}\right)$, Danan Arief Desprianto, Isnaeni Nurrohmah, Rahma Khairunisa Nursalamah, Panca O. Hadi Putra

Universitas Indonesia, Depok, Indonesia

harrybs@cs.ui.ac.id

\begin{abstract}
Indonesia Open-Educational Resources (IOER) need an approach to design a massive open online course (MOOC) interaction to accommodate users' needs and suggestions. The purpose of this research is to implement customer journey as an alternative approach for developing a MOOC's interaction design. An online questionnaire, requirement gathering, prototyping, and contextual interview were used to support this research. As a result, there are three phases of customer journey consisting of planning, learning, and completion. In addition, a MOOC interaction design prototype was produced to depict the result.
\end{abstract}

Keywords-Online learning, massive open online course, customer journey

\section{Introduction}

E-learning is one of information and communications technology (ICT) utilizations for educational purposes. E-learning is defined as instructions delivered by digital devices in order to support the learning process. The existence of e-learning gave birth to distance learning, a concept of learning process in which educational material can be accessed by students anytime and at anywhere [1]. The most recent innovation in distance learning is the massive open online course (MOOC) that arranges a collection of learning materials that is combined with a learning assessment scoring scheme [2]. Popular examples of MOOC include, among others, Coursera, edX, and Udacity.

The Faculty of Computer Science of Universitas Indonesia, specifically the Digital Library and Distance Learning (DL2) laboratory, has been developing an online learning platform called Indonesia Open-Educational Resources (I-OER). I-OER implements the open-education resources paradigm which was initiated by The Indonesian Association of Higher Education in Computer Science (APTIKOM) that has chosen to promote open education in Indonesia. The I-OER comprises three components [3], namely Open Content (OCT), Open Courseware (OCW), and Open Education (OED).

OCT is a collection of educational contents. An individual or institution can become a contributor and share educational contents, such as presentations, modules, tools, and journals. Meanwhile, OCW comprises groupings of educational contents, arranged into educational packages. This arrangement aims to facilitate users to study 
a particular topic. An individual or institution can also become a contributor. The last component is OED which facilitates access to complete educational packages, including educational materials, assignments, and grading. A professional, such as a professor, teacher, lecturer, or institution, can become a contributor to OED. Moreover, learners can access the educational materials as they access an online class.

However, the OED component has not been defined adequately and requires a practical interaction design to accommodate users' need. Interaction design focuses on creating an engaging user-interface design suitable for user behavior [4] and designing an interactive product to support how people communicate and interact in daily life [5]. Interaction design is constructed through four activities, namely developing user needs, creating an alternative design, implementing a prototype, and evaluating the prototype. To adapt the design to the users, the involvement of the users is essential in interaction design [6]. Thus, to enhance the user experience of I-OER, an implementation of a purposeful approach was needed.

In this research, we applied the customer journey to adapt the user experience of IOER interaction design [7]. The customer journey is the visualization of users' actions to attain their goals and their viewpoint on the process or the service given [8][9]. Essentially, it visualizes the experience of users when they try to achieve a particular goal. In the implementation, journey mapping arranges the sequence of user goals and actions related to the framework of time. The framework consists of the opinion and emotion of the users who later form a narration. The summary of the narration is then visualized to describe the insight of design process information [10]. Users' involvement is crucial in customer journey because users have individual and dynamic preferences [11]. In other words, it is a challenge for MOOC providers to deliver a high-quality interaction design to increase customer experience throughout the customer journey [12].

The customer journey has five general elements. The first element is the point of view which visualizes the actor. In a customer journey map, there is only one point of view (one actor). The second element is a scenario, which determines the specific context of experience to be mapped. The third element is an action which establishes the pattern/idea and emotion. The fourth element is the touchpoint and channel. Touchpoint is a situation when users interact with an organization, and channel is the communication method of the touchpoint. The last element is the insight and ownership. The insights obtained from the customer journey, mainly opportunities to improve, will be forwarded to relevant departments to be addressed [13]. Figure 1 shows the framework of the customer journey map [14]. 


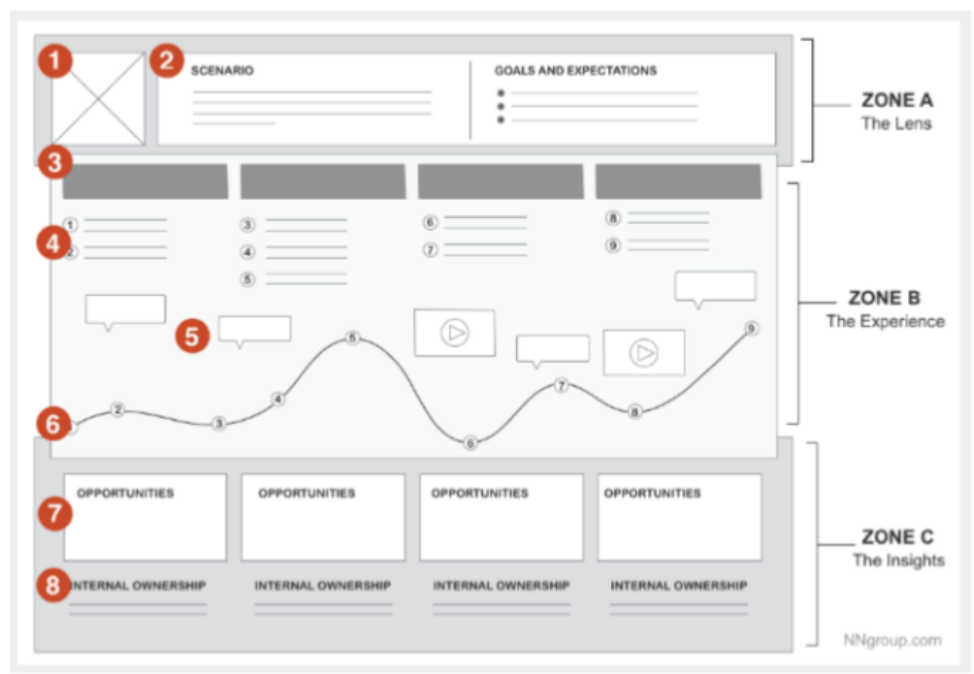

Fig. 1. The Framework of the Customer Journey Map

(Image source: [14])

This research aims to understand the customer journey for I-OER development. The result of customer journey research can be used to analyze the interaction design of I-OER. The data which contributed to the generation of the customer journey were gathered through a contextual interview. Contextual interview is an interview process where the researcher observes and listens to how users work in their environment. The process is informal and uses no task and no script. Based on [11], there are three phases of a contextual interview. The first phase is introduction, i.e. when the researcher and users develop trust and communication. The general activities in this phase are the introduction and the description of the goal and any related information. The second phase is the main body, i.e. when the researcher executes the plan and conducts the observation. The third phase is wrap up, i.e. the phase when the researcher announces the result of the observation and the conclusion for the users. This phase aims to clarify any misinterpretation from the researcher. At the end of this research, we expect to obtain interaction design prototype of I-OER that can accommodate user needs in order to help them attain their goals. The enhancement of interaction design is meant to increase the attractiveness of MOOC. Moreover, the interaction design is expected to facilitate the learners to attain education. 


\section{Materials and Method}

This section discusses a series of methods used including any materials gathered in completing this research. As an overview, this research comprises two major analysis phases (see Fig. 2). In the first phase, we designed and validated a questionnaire intended to survey user's behavior and expectation. Consequently, once the instrument was tested and validated by experts, it was distributed to potential respondents. Data collected through survey questionnaire were further analyzed as requirements or inputs for the next phase.

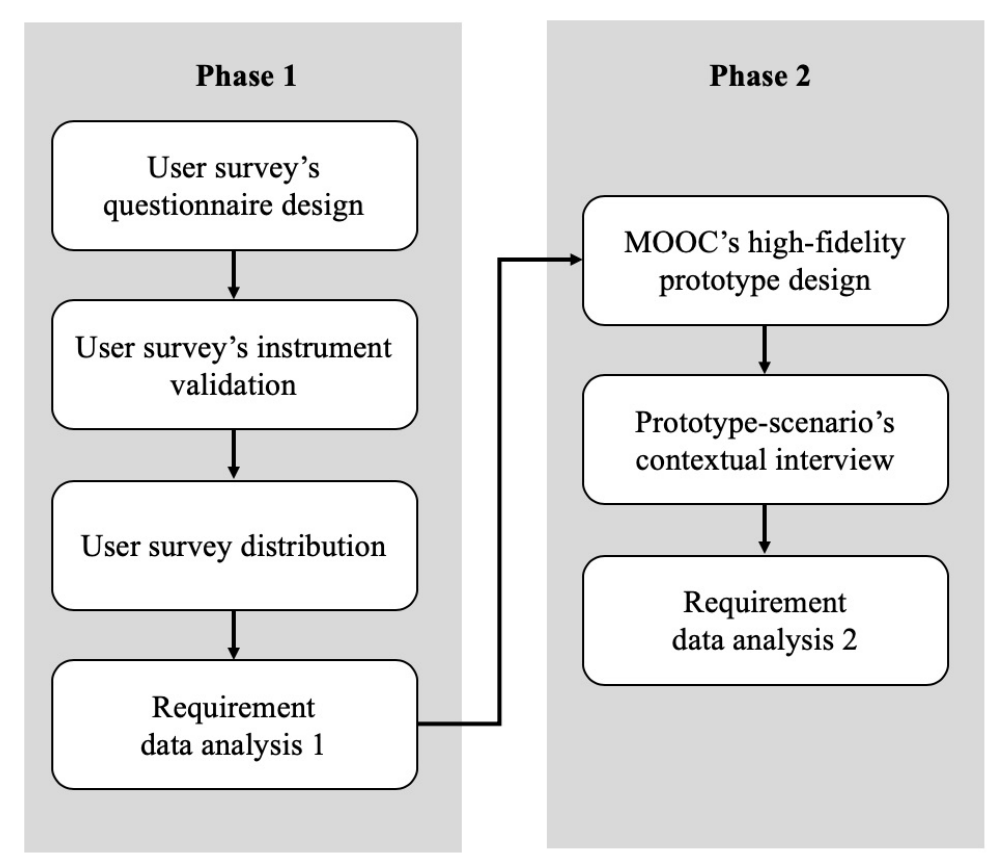

Fig. 2. An overview of research methods used in this research

In the second phase, based on the requirements gathered, we designed a highfidelity prototype. To test the prototype, we conducted a contextual interview which thereafter produced a customer journey report. The results of the contextual interview were then used as input for further requirement analysis. Subsequent subsections further describes all these research activities conducted in more detail.

\subsection{Data collection and requirement analysis 1}

In this part, we conducted a survey to collect information about MOOC users' behavior and expectation. The survey instruments consist of two parts. The first part identifies the respondents' demographic background, while the other part identifies 
the respondents' experience regarding MOOC utilization. Table 1 below shows the survey question regarding the second part.

Table 1. Survey Questions

\begin{tabular}{|c|l|}
\hline No. & \multicolumn{1}{|c|}{ Question } \\
\hline 1. & Have you ever used MOOC? \\
\hline 2. & Have you ever been a student in a MOOC? \\
\hline 3. & As a MOOC student, what motivates you to use MOOC? \\
\hline 4. & As a MOOC student, what makes you happy when using MOOC? \\
\hline 5. & As a MOOC student, what is it that you do not like about MOOC? \\
\hline 6. & $\begin{array}{l}\text { How often do you finish a class in MOOC? } \\
\text { If you never finished a class, what were the reasons? } \\
\text { If you ever finished a class, what were the reasons? }\end{array}$ \\
\hline 7. & If you are a MOOC student, what is your expectation regarding the MOOC? \\
\hline 8. & $\begin{array}{l}\text { Are you interested in using MOOC made by Indonesia? } \\
\text { If you ever used Indonesian MOOC, what were the strengths? } \\
\text { If you ever used Indonesian MOOC, what were the weaknesses? } \\
\text { Without considering the Indonesian MOOC experience, have you had any idea for Indonesian } \\
\text { MOOC? }\end{array}$ \\
\hline
\end{tabular}

Before the survey was carried out, it was tested to several potential respondents to ensure that the instruments could be easily understood in an expected manner. Additionally, it was also validated by an expert. The survey was distributed to the potential respondents via social media, such as Line, WhatsApp, and Facebook. From the survey, data were collected from 199 respondents. However, there were only 182 respondents who had previously used MOOC, and only these respondents were considered in this study.

\subsection{Prototype design and implementation}

Data gathered from the survey were analyzed and used to create a design prototype of MOOC which had a specific purpose of functionality. It was developed by using a high-fidelity prototype builder named "Justinmind". Since a high-fidelity prototype enables interactivity, the prototype could simulate and deliver the actual interaction of the system.

\subsection{Contextual interview}

Through this method, an observation was conducted and several questions were asked to the respondents. In a contextual interview, participants were invited to conduct scenarios using the previously developed prototype. Before conducting the customer journey research, we staked out the possible methods to be used. As this customer journey is related to I-OER interaction design, there were several essential things to be considered, such as activity, opinion, feeling, and opportunity of the participants. Data based on each participant were generated and delivered as a customer journey report. 
The customer journey report was formed in a set of tables which represent every scenario. This report visualized the journey of the customer and was used in the second phase of the requirement analysis. The customer journey was separated into steps needed when using MOOC. Then, it was visualized as a customer journey diagram. The customer journey diagram focuses on possible actions that can be done by the users in I-OER website.

\section{$2.4 \quad$ Requirement analysis 2}

This phase was necessary to uncover new findings and strengthen the requirement analysis in the first phase. The requirement was gathered from contextual interview analysis by identifying improvement probability from scenarios which were taken by the participants. The critical improvements were prioritized by considering the amount of probability and difficulty. Results from this phase were adopted to enhance the prototype.

\section{$3 \quad$ Results and Discussion}

\subsection{Data collection results}

From the data collection process, 199 participants filled out the survey. However, there were only 99 male participants (54\%) and 83 female participants (46\%) who had ever used MOOC. Based on the categories that support the use of MOOC, we assembled participants' preferences with the closest similarity and used these as the recommendation for the requirements. The preferences were analyzed as follows.

Motivation for using MOOC. The participants had several motivations for using MOOC. Most of them used MOOC because they wanted to study specific new topics, some of which could support their current knowledge. They wanted to join the course without face-to-face interaction and update their information about the topics. Obtaining certification of expertise and joining communities of their interests were also two of the participants' motivations. They also wanted to use MOOC with an attractive interface.

MOOC previously used. The participants used numerous MOOCs, either from Indonesia or outside Indonesia. Based on the survey, there were 10 MOOCs most used by the participants, which are Coursera (78), edX (63), Udacity (39), IndonesiaX (26), Codeacademy (25), Khan Academy (21), Udemy (20), Futurelearn (18), Zenius (13), MIT OCW (6), and Quipper (6).

Course topic. Based on our survey, the participants had taken several courses based on their preference. As the participants have different backgrounds, there were also different categories in choosing MOOC course topics. The 10 most taken topics including Programming and Computing (119), Language and Literature (46), Social Science (44), Science (43), Business and Management (32), Mathematics (30), Algorithm (25), User Experience and Design (22), Data (20), and Personal Development (16). 
Reasons for choosing MOOC. Each participant had several reasons for choosing MOOC. Most of them chose MOOC based on the availability of the preferred topic. Ease of use and completeness are considered. Besides these, they chose MOOC based on the conformity of the materials with their problems. Attractive interfaces and upto-date information are also the main attractions. The rewards such as certification are also important reasons why they chose MOOC. Furthermore, MOOC was chosen because of the existence of forums which support the communication between the users.

The preferred and not-preferred things from MOOC used. Some participants preferred to use MOOC because the instructors are communicative and have competency in their fields. Furthermore, the materials are applicable, easy to understand, enjoyable, up-to-date, complete, trustworthy, and interactive. However, not all participants agreed with these. Some of them thought that the materials should be improved and more accessible. MOOC organizers should also improve their website.

Rate of MOOC completion. Based on the survey, 132 participants had completed a MOOC course at least once, whereas the rest had never done so. Table 2 shows the participants' MOOC course completion experience.

Table 2. Rate of MOOC Completion

\begin{tabular}{|l|c|}
\hline \multicolumn{1}{|c|}{ Rate of completion } & Frequency \\
\hline Never & 52 \\
\hline $1-2$ times & 78 \\
\hline $3-4$ times & 30 \\
\hline $5-6$ times & 3 \\
\hline More than six times & 19 \\
\hline
\end{tabular}

Reasons for finishing and not finishing MOOC. Participants who had completed a course in MOOC cited their self-motivation and commitment as their reasons for completing it. They wanted to understand the new material and needed material comprehension or references. Some did so because they needed expertise in certain areas, whereas others finished a course because they needed the materials to support their work or study. They also wanted to get some rewards or certification. Some participants just wanted to spend their time by doing a meaningful activity. Another reason for finishing a MOOC course was because the materials were delightful, useful, easy to understand, profound, and sustained. However, for those who had never finished any course in MOOC, the main reason is time management. They were not committed and had other activities.

Students' Expectation of MOOC. As a student, the participants expected MOOC to provide rich and necessary course topics that could correspond with their problems. The up-to-date information, along with an easy-to-use and attractive interface, could also improve the use of MOOC. They also expected the availability of a certificate when completing a course.

Interest in using Indonesian MOOC. Generally, most participants (157) were interested in using Indonesian MOOC, while the rest had no interest in using Indonesian MOOC. In other words, the interest in using Indonesian MOOC is high. 
Strengths and weaknesses of Indonesian MOOC. The participants have been using several Indonesian MOOCs. Based on the survey, the strength of the Indonesian MOOCs is that the topics are more relevant to Indonesia's current condition. The use of Indonesian language helps users to understand the courses, as well as making the content more enjoyable and easy to understand. The MOOC also has an appealing, simple, easy to use, and effective interface. However, it could be enhanced by delivering complete and up-to-date materials.

Suggestions for Indonesian MOOC. The participants suggested improving the use of MOOC in Indonesia by increasing the categories and contents. The contents should be engaging, complete, up-to-date, interactive, applicable, and easy to understand. Indonesian MOOC should not only follow the MOOC materials abroad but also adjust them with the current condition in Indonesia. The organizer could also improve the application by completing the features and creating a high-quality interface.

\subsection{Requirement gathering}

Based on the results of our questionnaire analysis, the requirements for the MOOC application were compiled and shown in Table 3 below. Categories 1 to 10 were implemented into a prototype, while categories 11 to 14 were used to support the development.

Table 3. Requirement Analysis I

\begin{tabular}{|c|c|c|}
\hline No & Category (Code) & Requirements \\
\hline 1. & Website performance (KW) & $\begin{array}{l}\text { Can be accessed quickly } \\
\text { Multiple browser compatibility } \\
\text { Multiple hardware or gadget compatibility }\end{array}$ \\
\hline 2. & Class instructional design (KDI) & $\begin{array}{l}\text { Course time using Indonesian style } \\
\text { Provide alternate time } \\
\text { Brief information about materials } \\
\text { Provide class objectives } \\
\text { Provide outlines } \\
\text { Provide class instructor information } \\
\text { Free access, payable certificate } \\
\text { Provide course review } \\
\text { Assessment based on tasks, quizzes, exams, and activeness } \\
\text { Synchronized materials (website and mobile) } \\
\text { Use Indonesian language } \\
\text { Provide progress information }\end{array}$ \\
\hline 3. & Communication tools (KAK) & $\begin{array}{l}\text { Provide forum discussion } \\
\text { Display online user } \\
\text { Provide alternative questions using video call } \\
\text { Can send a message to the instructor }\end{array}$ \\
\hline 4. & Notification (KN) & $\begin{array}{l}\text { Provide email notification } \\
\text { Notify deadlines } \\
\text { Notify material updates }\end{array}$ \\
\hline 5. & Instructors (KKP) & $\begin{array}{l}\text { Display instructor's profile } \\
\text { Collaborate with an expert instructor } \\
\text { Permanent instructor } \\
\text { Instructor provides feedback } \\
\text { Provide a special class with professors }\end{array}$ \\
\hline
\end{tabular}




\begin{tabular}{|c|c|c|}
\hline No & Category (Code) & Requirements \\
\hline 6. & $\begin{array}{l}\text { Availability of class selection } \\
(\mathrm{KPI})\end{array}$ & $\begin{array}{l}\text { Provide a list of classes } \\
\text { Class search feature }\end{array}$ \\
\hline 7. & Class materials (KMK) & $\begin{array}{l}\text { Provide videos } \\
\text { Provide a link of references } \\
\text { Complete video features } \\
\text { Provide discussion materials } \\
\text { Provide a video summary } \\
\text { Materials are easy to understand, enjoyable, update, com- } \\
\text { plete, trusted, and applicable } \\
\text { Visualization } \\
\text { Suitability between material weight and schedule }\end{array}$ \\
\hline 8. & Payment (KKP) & $\begin{array}{l}\text { Provide a payment method to get a certificate } \\
\text { Use Indonesian Rupiah (IDR) }\end{array}$ \\
\hline 9. & Certificate (KS) & $\begin{array}{l}\text { Provide certificate } \\
\text { Provide a certificate-taking feature } \\
\text { Provide a free and payable certificate }\end{array}$ \\
\hline 10. & Assessment (KAU) & $\begin{array}{l}\text { Provide questions, quizzes, tasks, exams } \\
\text { Provide a variety of questions, quizzes, and tasks with their } \\
\text { solutions } \\
\text { Quiz for every material } \\
\text { Complete discussion quizzes } \\
\text { Provide assessment results }\end{array}$ \\
\hline 11. & Interface & $\begin{array}{l}\text { Tidy, attractive, simple, effective, and easy to use. } \\
\text { Minimize user errors. }\end{array}$ \\
\hline 12. & Advertisements and cooperation & $\begin{array}{l}\text { MOOC can promote their business by giving the best price } \\
\text { and cooperating with educational institutions to develop the } \\
\text { course. }\end{array}$ \\
\hline 13. & Subject conversion & $\begin{array}{l}\text { Provide course conversion charts, so students can convert } \\
\text { their courses to obtain higher education credits. }\end{array}$ \\
\hline 14. & Privacy & MOOC account authentication \\
\hline
\end{tabular}

\subsection{Prototype design and implementation}

Based on the above compilation of requirements, we designed and implemented a high-fidelity prototype for MOOC, especially I-OER. In general, the prototype was developed to deliver consistency and cater to universal usability. The prototype development was separated into four parts, as follows.

Homepage. This is the first page that appears if we access I-OER in the open education section. This page contains the login and register interface for the users. It also displays brief information about I-OER open education support with classes with the highest rating.

Class category. This is a page which shows the list of classes in open education. The classes are grouped based on field of study. A searching tool is also provided to help users. This part is the implementation of KPI requirements.

Class preview. The class preview page is provided to give information about a class. The information that can be found in this part consists of class name, instructors, class description, class goals, and class review. This part is the implementation of KDI, KKP, and KS requirements.

Class. The class page is the implementation of a MOOC course in I-OER as shown in Figure 2. A class consists of four sections, including materials, news, forum, and 
grade. The material section contains outlines (as the implementation of KDI and KMK requirements), weekly materials (as the implementation of KDI and KMK requirements), and assessments (as the implementation of KAU requirements). The news section contains class news (information) from the instructor to the students. The forum section contains threads being discussed in the class and chatting or video call interface. The news and forum sections are the implementations of KAK and KKP requirement. The last section is the grade section which shows the information about class grading, including assessment components and class completion. Its section is the implementation of KDI and KAU requirements.

Certificate taking. The last implementation of the I-OER was the certificate. This feature shows the interface that accommodates students to get their certificate after completing a class. The certificate is the implementation of KKP and KS requirements.

\subsection{Contextual interview}

The prototype was evaluated through contextual interviews with 30 participants, consisting of university students and full-time workers. Each participant was asked to do six scenarios which were joining a class, accessing materials, accessing news, discussing in a forum, looking for a grade, and taking a certificate. Based on the analysis, the participants carried out the three main steps: class planning, class learning, and class completion. Each step consists of a sequence of actions, as shown in Figure 3. In the customer journey, we discovered users' opinions and feelings. Based on those, we looked for probability as the result of a contextual interview analysis. The contextual interview analysis was done by analyzing six scenarios and one outside scenario probability. Each probability corresponded with the theory developed by Yousef et al., which consists of instructional design, grading suggestion, interface suggestion, video suggestion, learning and social suggestion, and learning analytics.

\subsection{Requirement analysis 2}

Based on the probability analysis, several recommendations were compiled as the results of requirement analysis part 2 . However, not all the recommendations were accommodated in the prototype's implementation. The requirements were selected based on their appearance probability rate and difficulty.

Figure 3 shows the customer journey of the IOER. It consists of three parts: Planning part, Learning part, and Completion part. In the Planning part, the students can explore useful information about a particular class, such as rating, payment info, and institution information. In class review, information about the number of joining students was added. A notification field was added to the right side bar to help the student access the class notification. While accessing the Learning part of the system, the students can learn the materials, completing quiz and exam, read news, participate in the discussion forum. In addition, in the Completion part, the students can proceed their certificate if they pass required learning activities and assessments. In the certifi- 
cation page, it shows all certificates related to the class page; thus, a student could quickly get their certificate. We also improved the payment method mechanism.

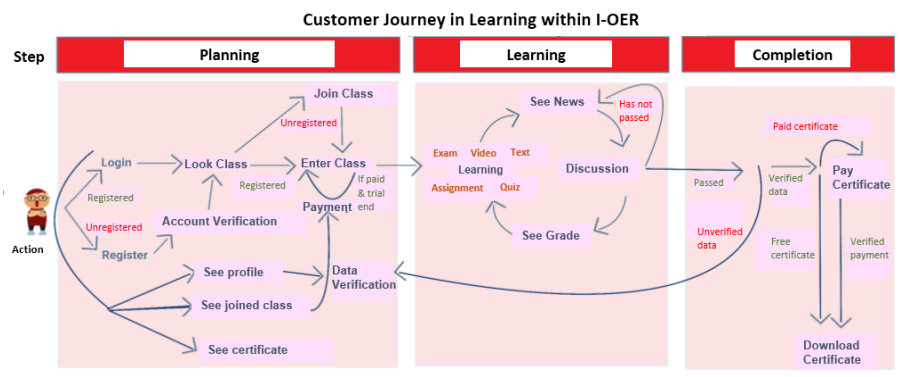

Fig. 3. Customer Journey of I-OER

Figure 4 shows the implementation of Class Page. In the page, the task submission mechanism was fixed, which also improved the students' experience by giving a checklist for materials that had been accessed. The page consists of several tabs: learning materials (Materi), news (Berita), discussion forum (Forum), and grade (Nilai).

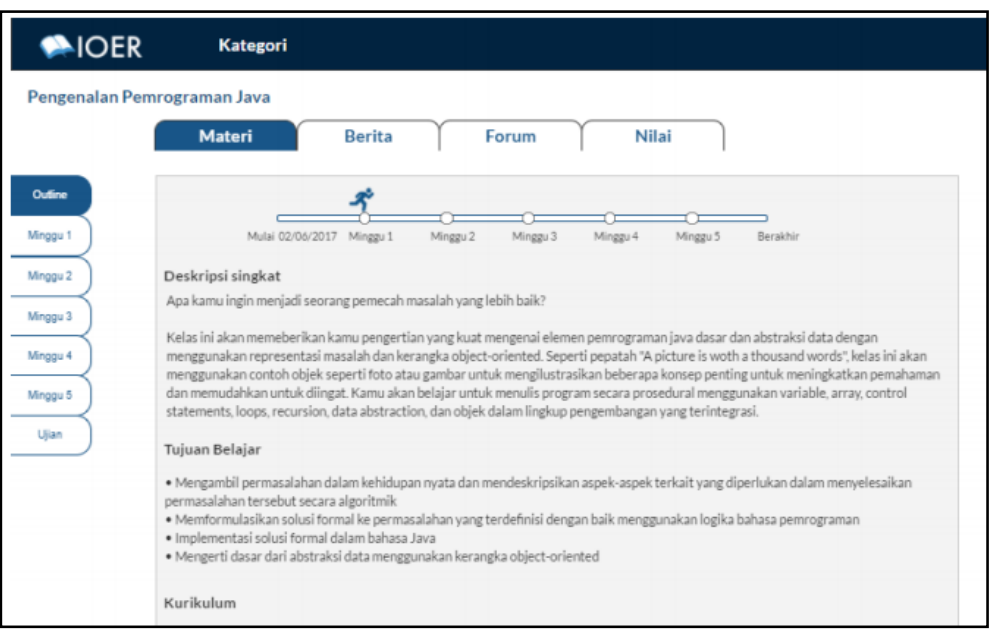

Fig. 4. Implementation of Class Page

\section{Conclusion}

Based on our research results and discussion, the questionnaire survey was useful for formulating requirements in phase one. The requirements were incorporated later into the interaction design process, specifically into the creation of a prototype. Additionally, we found six scenarios which are essential to the process, consisting of join- 
ing the class, learning material access, accessing news, forum activity, and certificate taking. A contextual interview was performed for each scenario to identify the customer journey. There are three main actions in the customer journey, including planning, learning, and completion. Customer journey results were analyzed to identify the opportunity for I-OER improvement.

The interaction design process of I-OER website consisted of several steps. The first was identifying the requirements based on the questionnaire data. The second step was translating the requirements into the design. The next step was designing and creating the functionality of the MOOC prototype. The last step was conducting a contextual interview to evaluate the prototype and identify the improved requirements.

\section{$5 \quad$ References}

[1] Kemenristekdikti, "Panduan Pelaksanaan PJJ," 2016. [Online]. Available on: http://kuliah daring.dikti.go.id/s/berkas/view/1/panduan/pii.

[2] S. M. Stefan, "MOOC? OCW? Which one?," 2 Oct. 2015. [Online]. Available on: http:// sites.uci.edu/opencourseware/ blog/2015/10/02/moococw-which-one/.

[3] H. B. Santoso, B. A. Cenka, B. Priyogi, A. A. G. Y. Paramartha, and Z. Hasibuan, "Platform development and design evaluation of the Indonesia Open Educational Resources," in International Conference on Computers in Education, China, 2015.

[4] Usability.gov, "Interaction design basic," [Online]. Available on: https://www.usability. gov/what-and-why/interactiondesign.html.

[5] J. Preece, H. Sharp, and Y. Rogers, Interaction Design: Beyond Human-computer Interaction $4^{\text {th }}$ Edition, New York: Wiley, 2015.

[6] A. Richardson, "Using customer journey maps to improve customer experience," 15 November 2010. [Online]. Available on: https://hbr.org/2010/11 /using-customer-journeymaps-to.

[7] A. Folstad and K. Kvale, "Customer journeys: A systematic literature review," Journal of Service Theory and Practice, vol. 28, pp. 196-227, Nov. 2017. https://doi.org/10.1108/js tp-11-2014-0261

[8] R. Halvorsrud, K. Kvale, and A. Folstad, "Improving service quality through customer journey analysis," Journal of Services Theory and Practice, vol. 26, pp. 840-867, May 2015. https://doi.org/10.1108/jstp-05-2015-0111

[9] S. Nenonen, H. Rasila, J. M. Junnonen, \& S. Karna, "Customer Journey - a method to investigate user experience," In Proceedings of the Euro FM Conference Manchester (pp. 54-63), 2008.

[10] K. N. Lemon and P. C. Verhoef, "Understanding customer journey experience throughout the customer journey," Journal of Marketing, vol. 80, pp. 69-96, Nov. 2016. https://doi. org $/ 10.1509 / \mathrm{jm} .15 .0420$

[11] K. Kaplan, "When and how to create customer journey map," 31 July 2016. [Online]. Available on: https://www.nngroup.com/articles/customer-journey-mapping/.

[12] G. V, "Contextual interviews and how to handle them," August 2016. [Online]. Available on: https://www.interaction-design.org/literature/article/contextual-interviewsand-how-tohandle-them.

[13] A. M. Yousef, A. M. Chatti, U. Schroeder, and M. Wosnitza, "What drives a successful MOOC? An empirical examination of criteria to assure design quality of MOOC" in Inter- 
national Conference on Advanced Learning Technologies, 2014. https://doi.org/10.1109/ic alt.2014.23

[14] K. Kaplan, “When and how to create customer journey maps, ”2016 https://www.nngroup. com/articles/customer-journey-mapping/

\section{Authors}

Harry Budi Santoso, $\mathrm{PhD}$ is a faculty member at the Faculty of Computer Science in Universitas Indonesia (UI). He received his BS and MS in Computer Science from Universitas Indonesia (UI), and his PhD from the Department of Engineering Education at Utah State University, in the USA. He has taught several courses at UI (e.g. computer-assisted instruction, computer and society, human-computer interaction). $\mathrm{He}$ is also Head of the Digital Library and Distance Learning Laboratory. His research interests includes learning personalisation, metacognition, multimedia content, user experience and distance learning.

Danan Arief Desprianto is presently working as iOS Software Engineer in Bukalapak (one of the leading online marketplace in Indonesia) since 2017. He received B.Sc. (computer) degree from Universitas Indonesia (UI). His research interests include user experience, user interface, mobile application development, and e-learning.

Isnaeni Nurrohmah is an alumnus of the Faculty of Computer Science, Universitas Indonesia (UI). She received her BS and Ms. in Computer Science from Universitas Indonesia. She was a research assistant at Digital Library and Distance Learning Laboratory who has interest in human-computer related studies specially e-Learning, e-Government, and e-Commerce topics.

Rahma Khairunisa Nursalamah is a bachelor in computer science from Universitas Indonesia (UI). She is a Senior User Experience (UX) Researcher at Halodoc, where she conducts studies to simplify healthcare in Indonesia. She has taught UX Design at Purwadhika Startup School and tutored Web Design and Programming at UI. She was also a research assistant at the Digital Library and Distance Learning Laboratory. Her current research interests include mobile health, teleconsultation, metacognition and user experience.

Panca O. Hadi Putra is a lecturer at the Faculty of Computer Science, Universitas Indonesia. He holds a B.Sc with honors in information systems from Sunway University, an M.Bus in business and information systems from College of Business and Economics, the Australian National University, and a Ph.D in computer science from the Faculty of Computer Science, Universitas Indonesia. Dr. Putra teaches both graduate and undergraduate courses, including systems analysis and design, enterprises systems, and e-commerce. His research interests are in the areas of design science in information systems, user experience, and digital learning.

Article submitted 2019-09-27. Resubmitted 2019-10-29. Final acceptance 2019-11-05. Final version published as submitted by the authors. 